\title{
Ozone and temperature decadal trends in the stratosphere, mesosphere and lower thermosphere, based on measurements from SABER on TIMED
}

\author{
F. T. Huang ${ }^{1,{ }^{*}}$, H. G. Mayr ${ }^{2}$, J. M. Russell III ${ }^{3}$, and M. G. Mlynczak ${ }^{4}$ \\ ${ }^{1}$ University of Maryland, Baltimore County, Maryland, 21250, USA \\ ${ }^{2}$ NASA Goddard Space Flight Center, Greenbelt, MD 20771, USA \\ ${ }^{3}$ Hampton University, Center for Atmospheric Sciences, Hampton, VA 23668, USA \\ ${ }^{4}$ NASA Langley Research Center, Hampton, VA 23681, USA \\ *retired
}

Correspondence to: F. T. Huang (fthuang@ verizon.net)

Received: 4 November 2013 - Revised: 26 May 2014 - Accepted: 1 July 2014 - Published: 11 August 2014

\begin{abstract}
We have derived ozone and temperature trends from years 2002 through 2012, from 20 to $100 \mathrm{~km}$ altitude, and $48^{\circ} \mathrm{S}$ to $48^{\circ} \mathrm{N}$ latitude, based on measurements from the Sounding of the Atmosphere using Broadband Emission Radiometry (SABER) instrument on the Thermosphere, Ionosphere, Mesosphere Energetics and Dynamics (TIMED) satellite. For the first time, trends of ozone and temperature measured at the same times and locations are obtained, and their correlations should provide useful information about the relative importance of photochemistry versus dynamics over the longer term. We are not aware of comparable results covering this time period and spatial extent. For stratospheric ozone, until the late 1990s, previous studies found negative trends (decreasing amounts). In recent years, some empirical and modeling studies have shown the occurrence of a turnaround in the decreasing ozone, possibly beginning in the late 1990s, suggesting that the stratospheric ozone trend is leveling off or even turning positive. Our global results add more definitive evidence, expand the coverage, and show that at mid-latitudes (north and south) in the stratosphere, the ozone trends are indeed positive, with ozone having increased by a few percent from 2002 through 2012. However, in the tropics, we find negative ozone trends between 25 and $50 \mathrm{~km}$. For stratospheric temperatures, the trends are mostly negatively correlated to the ozone trends. The temperature trends are positive in the tropics between 30 and $40 \mathrm{~km}$, and between 20 and $25 \mathrm{~km}$, at approximately $24^{\circ} \mathrm{N}$ and at $24^{\circ} \mathrm{S}$ latitude. The stratospheric temperature trends are otherwise mostly negative. In the mesosphere, the ozone trends are
\end{abstract}

mostly flat, with suggestions of small positive trends at lower latitudes. The temperature trends in this region are mostly negative, showing decreases of up to $\sim-3 \mathrm{Kdecade}^{-1}$. In the lower thermosphere (between $\sim 85$ and $100 \mathrm{~km}$ ), ozone and temperature trends are both negative. The ozone trend can approach $\sim-10 \% \mathrm{decade}^{-1}$, and the temperature trend can approach $\sim-3 \mathrm{Kdecade}^{-1}$. Aside from trends, these patterns of ozone-temperature correlations are consistent with previous studies of ozone and temperature perturbations such as the quasi-biennial (QBO) and semiannual (SAO) oscillations, and add confidence to the results.

Keywords. Atmospheric composition and structure (middle atmosphere - composition and chemistry)

\section{Introduction}

Atmospheric ozone and temperature trends from the stratosphere into the lower thermosphere are interesting both for scientific and pragmatic reasons. For years, until the late 1990s, measurements in the stratosphere have found that ozone amounts had been decreasing (negative trend), while temperature trends had remained mostly neutral or negative. From the late 1990s, there were indications from both measurements and models that, possibly due to decreases in ozone-depleting substances (ODS), a turning point may have been reached such that the negative ozone trends in the stratosphere would level out or even become positive. However, 
empirical studies were limited in their spatial coverage and by quality issues concerning the data. The World Meteorological Organization (WMO, 2010) noted that these observed ozone increases could not presently be attributed to ozonedepleting substances (ODS) decrease, due in part to observational uncertainty and other things, such as dynamics. Although the expectation is that ODS concentrations will decrease in time, its future rate of change, and its actual occurrence, are of course not certain. Kohlhepp et al. (2012) have found decreases in total column abundances of $\mathrm{HCl}$ and $\mathrm{ClONO}_{2}$, from 2002 to 2009, based on ground-based measurements from 17 stations spread over the globe. However, the results are not uniform and in some instances there have been some increases.

Obviously, more global measurements that extend the time span and spatial coverage of previous data, made after the late 1990s, would be valuable in validating and consolidating the actuality of the ozone turnaround.

Ozone and temperature data from the Sounding of the Atmosphere using Broadband Emission Radiometry (SABER) instrument (Russell III et al., 1999) on the Thermosphere, Ionosphere, Mesosphere Energetics and Dynamics (TIMED) satellite fill this gap in satellite data. The measurements are unique in the breadth of their information content, taken around the globe from about 20 to $100 \mathrm{~km}$, over $24 \mathrm{~h}$ in local solar time (1st) and since the beginning of 2002. This kind of information has not been available previously, especially from one instrument.

We believe that SABER measurements provide a new global data set for both ozone and temperature trends, as we are not aware of any comparable results covering this time period and spatial extent. For the first time, trends of ozone and temperature measured at the same times and locations are obtained, and their correlations should provide useful information about the relative importance of photochemistry versus dynamics over the longer term.

Because of the relatively small values of trends, and potential mathematical issues in their estimation, previous studies have emphasized statistical analysis to ensure the quality of the results.

However, we do not depend only on statistical and error analysis for this purpose. In the following, we take advantage of being able to compare our results with others, directly or indirectly, as follows:

1. We will show below that our ozone trends in the stratosphere compare favorably with those of the World Meteorological Organization (WMO, 2010), both in midlatitudes, where the trends are positive, and in the tropics, where the trends are negative.

2. For temperature, as discussed below, $\mathrm{Xu}$ et al. (2007) have also estimated temperature trends, over 5 years of data, using an earlier version (1.06 versus 1.07) of SABER data, and state their results satisfy $95 \%$ confidence levels. Our temperature trends in Fig. 3, also over
5 years, agree well with those of Xu et al. (2007), and consequently would also satisfy the significance criteria.

3. We will check consistencies in comparing our ozone with temperature trends. Our results show that in the middle and upper stratosphere, the ozone and temperature trends are generally negatively correlated with each other. These results are not unexpected, and have been noted in previous studies of ozone and temperature perturbations such as mean variations and the quasibiennial oscillations, although not for trends (Brasseur and Solomon, 2005; Garcia and Solomon, 1985; Finger et al., 1995). The probability that these correlations are fortuitous is extremely small. We discuss this in more detail below in Sect. 3 .

These give additional confidence to the reality of the estimated trends for both temperature and ozone, giving strong evidence that our results are not artifacts of the data or of the analysis.

\section{Data characteristics and analysis}

SABER ozone and temperature measurements have been analyzed with success over the past decade. We have derived ozone and temperature variations with periods from 1 day or less (diurnal variations) up to multiple years (semiannual oscillations (SAO) and quasi-biennial oscillations (QBO)). See Huang et al. (2010a, b, 2008). Studies by others for SABER temperature (diurnal tides) include Zhang et al. (2006) and Mukhtarov et al. (2009). For both ozone and temperature, these studies show that, for variations that are deviations from a mean state (e.g., diurnal variations, tides, SAO and QBO), SABER measurements are robust and precise. For example, zonal mean tidal temperatures agree with other measurements to within $\sim 1 \mathrm{~K}$ (Huang et al., 2010a), and zonal mean ozone diurnal variations agree with other measurements to within less than a few percent (Huang et al., 2010b). Deviations from a mean state also include variations such as trends. It is the systematic uncertainties (accuracy) that can be large, and the fluctuations about the mean state (precision) are relatively small. For analysis of data over long periods, the stability of the instrument and satellite orbital characteristics are also considerations, and these are discussed in Appendix B.

\subsection{Data characteristics}

The data are provided by the SABER project (version 1.07, level2A). They are interpolated to 4-degree latitude grids, and $2.5 \mathrm{~km}$ altitude grids, after which zonal averages are taken for analysis.

A feature of SABER data is that, unlike other satellites, the orbital characteristics of TIMED is such that SABER samples $24 \mathrm{~h}$ of local time, and can identify diurnal variations of 
ozone and temperature (e.g., thermal tides). This is especially important in the mesosphere and lower thermosphere, where the ozone and temperature diurnal amplitudes can be dominant. Even in the stratosphere, ozone and temperature diurnal variations may not be negligible (Huang et al., 2010a, b). For trend estimation, they need to be identified and accounted for.

\subsection{Data analysis}

\subsubsection{Trend estimation}

As noted earlier, we analyze zonal means of the SABER ozone and temperature data.

The trends are estimated in a similar manner as previously done by others, using multiple regression analysis (e.g., see Bevingtion and Robinson, 1992; Keckut et al., 1999) that includes the seasonal, quasi-biennial (QBO), and solar activity (f107) terms, on monthly values.

Our trend estimates are based on a least squares analysis of the equation

$$
\begin{aligned}
\mathrm{O}_{3}(t) & =a+b \cdot(t)+c \cdot S(t)+l \cdot 1 \mathrm{st}(t)+d \cdot \mathrm{f} 107(t) \\
& +g \cdot \mathrm{QBO}(t)+N(t)
\end{aligned}
$$

applied to the data, where $t$ is time, $\mathrm{O}_{3}$ is the ozone mixing ratio (or temperature), $b$ is the trend to be determined, $c$ is the coefficient for the seasonal $(S(t))$ variations, $l$ is the coefficient for local time variations, $d$ is the coefficient for solar activity (10.7 cm flux) and $g$ is the QBO. Although Eq. (1) is commonly used, it is a linear representation, while the equations governing the atmosphere variations are nonlinear. In addition, some studies include additional terms, such as the El Niño-Southern Oscillation (ENSO), volcanic eruptions and equivalent effective stratospheric chlorine (EESC). For the seasonal and local time terms, the SABER measurement has an additional complication in that it samples data at different local times, but it takes 60 days to cover the $24 \mathrm{~h}$. The variations with local time are embedded with the seasonal variations, and need to be separated from them. The method we use estimates both the diurnal and mean (seasonal, semiannual, annual) variations together. The algorithm performs a least squares estimate of a two-dimensional Fourier series where the independent variables are local solar time and day of year. The method is described in detail in Huang et al. $(2010 \mathrm{a}, \mathrm{b})$. The f107 term stands for fitting against the solar $10.7 \mathrm{~cm}$ flux, which is commonly used as a measure of solar activity. In 2002, the flux was near maximum of the $\sim 11$-year solar cycle, at about 180 solar flux units (sfu); it was near minimum in 2008 , with a value near $70 \mathrm{sfu}$, and at the end of 2012 the value was near $120 \mathrm{sfu}$. This last value was unusually low, since the previous maximum was about $180 \mathrm{sfu}$. The term $N(t)$ stands for the rest of the atmospheric variability including a random noise term, and is discussed further in Sect. 2.2.2 (Statistical and error considerations).

Figure 1 shows examples of the monthly temperatures ( $\mathrm{K}$, top row) at $40 \mathrm{~km}, 40^{\circ} \mathrm{S}$ latitude (left) and $40^{\circ} \mathrm{N}$, from
2002 to 2012. The bottom row shows corresponding plots for ozone mixing ratios (ppmv). The estimated trends are also shown with the monthly values, from which seasonal and local time variations have been removed. Note that the temperatures have negative trends, while the ozone trends are positive. We will discuss this in more detail below.

\subsubsection{Statistical and error considerations}

A commonly used criteria to indicate if an estimated trend is statistically significant is that its magnitude must be greater than $2 \sigma(\sim 95 \%$ confidence level), where $\sigma$ is the uncertainty of the trend estimate. However, the uncertainties (e.g., standard deviations) of the SABER measurements themselves, which are needed for obtaining the uncertainties in the trends, are not available. As a substitute for the data variances, we use the sample variance, namely, the sum of squares of the residuals, normalized by the number of degrees of freedom of the fit (e.g., Bevingtion and Robinson, 1992). The residuals are the differences between the fit of Eq. (1), without the term $N(t)$, and the data. Since not all physical variations are included in Eq. (1), it is likely that these residuals are overestimates of the data uncertainties, and would then also overestimate the trend uncertainties themselves, and as a balance, we also do not include $N(t)$ in the regression analysis. When $N(t)$ is not included, adjacent points in the residuals would likely be correlated, which would affect the estimate of the trend uncertainties. To analyze the effects of autocorrelation, Tiao et al. (1990) and Weatherhead et al. (1998, 2000), among others, have used first-order autoregressive (AR) processes for $N(t)$ to account for the data autocorrelations. This has the form $N_{i}=\alpha N_{i-1}+\varepsilon_{i}$, where $\alpha$ is a constant and $\varepsilon_{i}$ is part of a purely random set. Their analyses show that autocorrelation can significantly affect the uncertainties in the trends.

The use of AR processes can also help to study the issue of aliasing between trends and low-frequency variations, such as those due to solar activity. Following Tiao et al. (1990), if $\alpha$ is positive with a moderate value of 0.6 , then $N_{i}$ is of relatively low frequency, and can be "confounded" with the linear trend, and increases the uncertainties of the trend estimate, requiring a longer length of data. Tiao et al. (1990) derive expressions such that their product with the magnitude of the data uncertainty provides an estimate of the uncertainty of the trend. Their expressions are a function of the data length, and the trend uncertainty decreases as the data set length increases. Based on this, for our SABER data set of 11 years, the autocorrelation of the data can increase the uncertainty of the estimated trends by about a factor of 2 . Therefore, the existence of low-frequency variations which have the potential of aliasing with respect to the trends can increase the uncertainty of the trend estimates. We think it likely that our use of the fit residuals described above for data uncertainties would still overestimate the uncertainties 

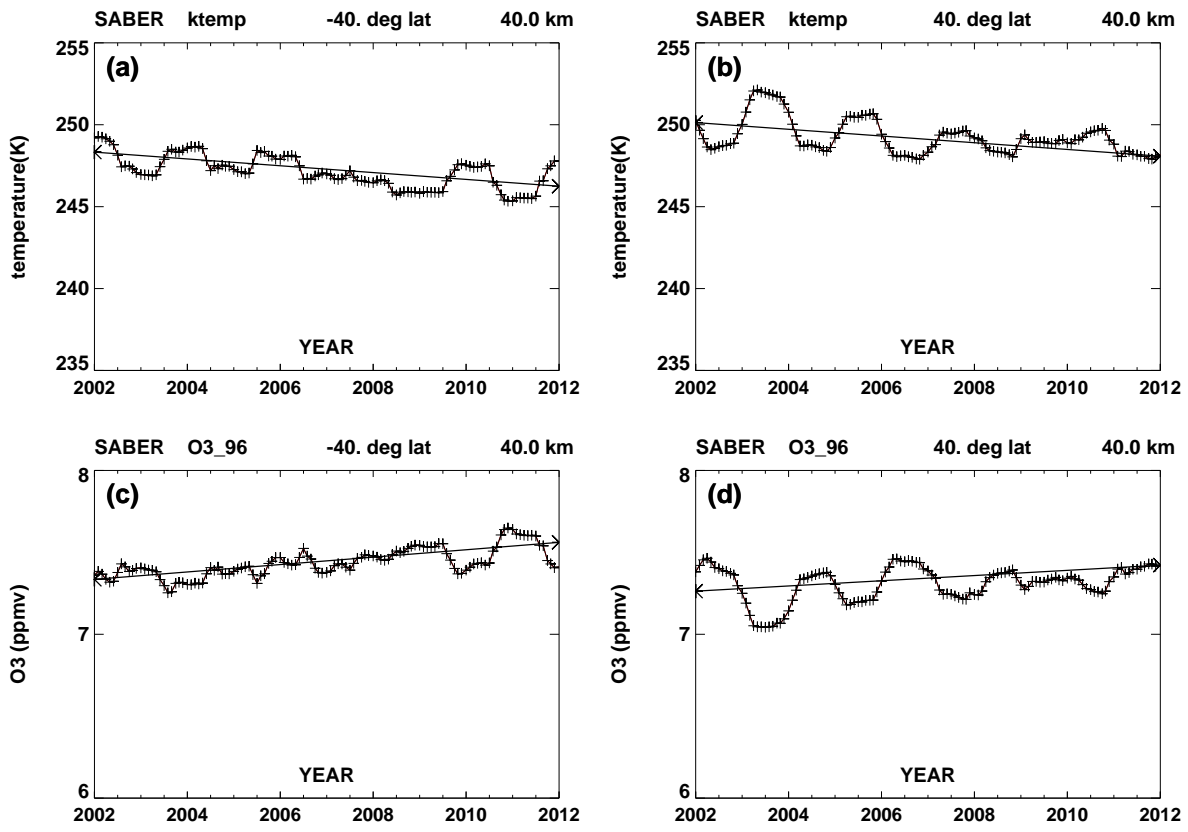

Figure 1. Top row: temperature trends (straight lines) from 2002 to 2012 at $40 \mathrm{~km} ; 40^{\circ} \mathrm{S}$ (left) and $40^{\circ} \mathrm{N}$ (right) latitude. Pluses denote data with seasonal and local time variations removed. Bottom row: corresponds to top row, but for ozone mixing ratios.

of the trends, so that our results would still be a conservative measure of the $2 \sigma$ criteria.

In Fig. 2, we show the values of our estimated trends for ozone and temperature. In Fig. A1 of Appendix A, the corresponding statistical significance of the trends are plotted, and it can be seen that the statistical significance of the salient features in Fig. 2 are generally well above the $2 \sigma$ level. In addition, as seen in Fig. 2, the contours of the trends are fairly smooth and regular. Although we do not do so here, if we take averages of adjacent latitudes $\left( \pm 4^{\circ}\right)$ and altitudes $( \pm 2.5 \mathrm{~km})$, the uncertainties in the estimated trends can be further reduced by a factor of 3 .

\section{Results and comparisons}

In the stratosphere, our results, based on measurements from 2002 through 2012 help substantiate and enhance evidence of positive ozone trends in the stratospheric northern and southern mid-latitudes. However, we find that in the tropics, the ozone trends are negative. Although model results and empirical studies are consistent with this, additional empirical evidence is still needed. For stratospheric temperature, we find mostly negative trends except in the tropics and lower stratosphere. We will see, that in this region, the temperature trends are mostly negatively correlated to the ozone trends. In the mesosphere, we find that the ozone trends are mostly flat. In the lower thermosphere, we find that both ozone and temperature trends are negative and therefore positively correlated. In this region, we are not aware of any other studies with which to compare. Figure 2 shows the ozone mixing ratio (ppmv, top row) and temperature (K, bottom row) trends in both decadal differences (left plots) and percent differences per decade (right plots). Positive values denote increases from 2002 through 2012. Note that the borders between brown-green areas denote zero contours, with brown and red areas denoting positive trends. The coordinates are altitude (20 to $100 \mathrm{~km}$ ) versus latitude $\left(48^{\circ} \mathrm{S}\right.$ to $\left.48^{\circ} \mathrm{N}\right)$.

In discussing the ozone and temperature trends, we will have occasion to consider the correlations between ozone and temperature, which can help in verifying our results for both ozone and temperature. The coincident and mutual variations of ozone and temperature have been previously studied in some detail and can provide useful information on the physical processes associated with each. For example, they can indicate the relative importance between photochemistry and dynamics that govern their behavior. For variations as a function of time over days, Barnett et al. (1975) showed that the temperature dependence of photochemical reaction-rates, by themselves, would lead to negative correlations in the upper stratosphere and mesosphere between ozone and temperature variations. Finger et al. (1995) found that ozone and temperature mean variations are mostly positively correlated (e.g., correlation coefficient) in the lower stratosphere and negatively correlated in the upper stratosphere, based on 16 years of satellite measurements. They also mention the use of correlations as a check on the quality of the data when the expected correlations do not hold.

Therefore, we can expect that in altitudes where ozone photochemistry dominates over dynamics, the ozonetemperature correlations will be negative, and in regions 

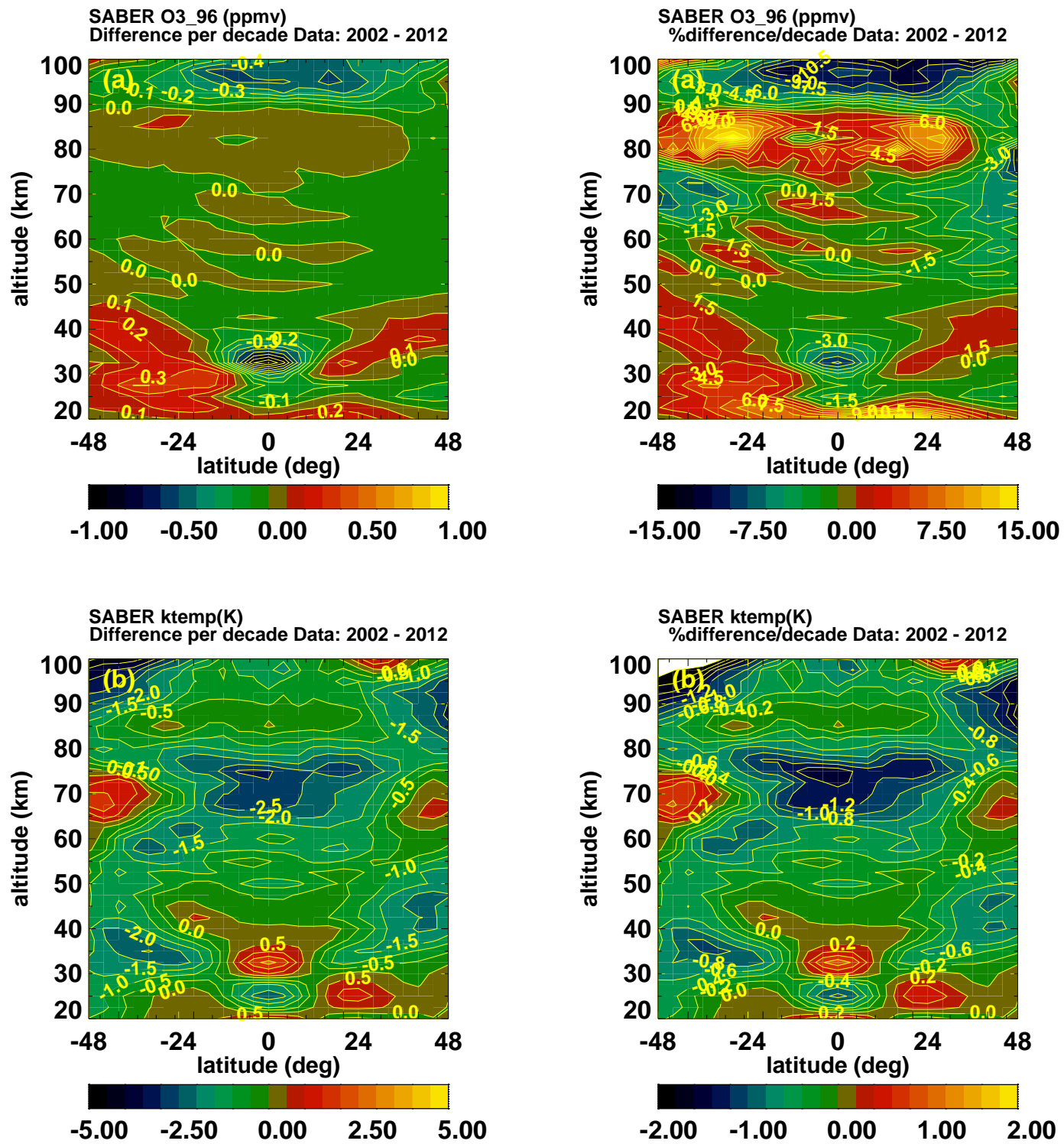

Figure 2. Ozone and temperature trends on altitude $(20$ to $100 \mathrm{~km})$ vs. latitude $\left(48^{\circ} \mathrm{S}\right.$ to $\left.48^{\circ} \mathrm{N}\right)$ coordinates. Top row left: ozone differences (ppmv) (2012-2002); right: percent differences. Bottom row: as in top row, but for temperature (K). Brown-green borders denote zero contours, with brown and red areas denoting positive trends.

where dynamics dominate, the correlations will generally be positive. We note that Rood and Douglass (1985) and Douglass et al. (1985) showed that dynamics can also cause anticorrelations between temperature and ozone, so there can be exceptions.

Brasseur and Solomon (2005) (see their Fig. 5.11, or Fig. 11 of Garcia and Solomon, 1985) noted that between $\sim 30 \mathrm{~km}$ and $\sim 75 \mathrm{~km}$, photochemistry is dominant, leading to negative ozone-temperature correlations. Below $\sim 25 \mathrm{~km}$ and above $\sim 85 \mathrm{~km}$, photochemistry no longer dominates. There are transition regions near $25-30 \mathrm{~km}$ and $75-85 \mathrm{~km}$, which are latitude dependent. As discussed below, it can be seen from Fig. 2 that our ozone-temperature correlations are generally consistent with this view, being mostly positive below $\sim 25 \mathrm{~km}$ and above $\sim 85 \mathrm{~km}$, and mostly negative between $\sim 30$ and $50 \mathrm{~km}$. In our analysis (Huang et al., 2008) of ozone and temperature QBO and SAO, also based on SABER data, we have found that their corresponding ozonetemperature correlations agree with this view, being mostly positive in the lower stratosphere and lower thermosphere, with negative correlations in the upper stratosphere and in the mesosphere.

Trends are represented by straight lines, as in Fig. 1, and the "correlation" is simply determined by the sign of the slopes of the trends (positive or negative) and whether they agree or disagree. If the ozone and temperature trends are 
both positive or both negative, then the correlation is positive. Otherwise (slopes have different signs), the correlation is negative. In Fig. 1, the corresponding slopes of the ozone and temperature trends have opposite signs, so they are negatively correlated. In Fig. 2, the blue and green colors represent negative slopes while the brown, red and yellow colors represent positive slopes; therefore, so at a given latitude and altitude, it is straightforward to discern positive or negative correlations in Fig. 2, simply by comparing the respective colors between ozone and temperature.

Consistent with this expectation, it can be seen in Fig. 2 that the ozone-temperature trends are mostly positively correlated below $\sim 25 \mathrm{~km}$ and above $\sim 85 \mathrm{~km}$, and mostly negatively correlated from $\sim 30$ to $50 \mathrm{~km}$. The probability that these expected correlations are accidental or fortuitous is of course very small. Therefore, the comparisons can provide confidence for both the ozone and temperature trends. In much of the mesosphere $(50-80 \mathrm{~km})$, our estimated ozone trends are near zero and not statistically significant.

\subsection{Stratosphere (20 to $50 \mathrm{~km}$ )}

\subsubsection{Stratospheric ozone}

In Fig. 2, the stratospheric ozone increases at mid-latitudes are statistically significant, generally from $5 \sigma$ to $10 \sigma$ and more (see Fig. A1 of Appendix A). It is only in the northern mid-latitudes between 25 and $35 \mathrm{~km}$ where our results show a weak negative trend that the values are not statistically significant. In the tropics up to $35 \mathrm{~km}$, the ratios are generally near $5 \sigma$ or greater. In the northern mid-latitudes $\left(\sim 20\right.$ to $48^{\circ}$ ), up to $50 \mathrm{~km}$, the ratios are comparable, except in the area between $30-48^{\circ} \mathrm{N}$ and up to $35 \mathrm{~km}$.

For the stratosphere, numerous studies (e.g., World Meteorological Organization (WMO), 2010, and references therein; Randel and Wu, 2007; McLinden et al., 2009) have analyzed data from 1979 through 2005 or later, and have found that prior to the late 1990s, stratospheric global ozone trends from the southern to northern mid-latitudes have been negative, with ozone mixing ratios decreasing by up to several percent or more per decade, except possibly in the lower stratosphere in the tropics, where the trend was mostly neutral.

Because abundances of ozone-depleting substances (ODS) have declined in recent years, there are some expectations that beginning the late 1990s, the negative trends would begin to level off or even become positive. We note there have been studies that suggest dynamics could contribute to these trends as well. More recently, some studies have separated data from before 1996 and after 1996 for trend analysis (e.g., World Meteorological Organization (WMO), 2010, and references therein; Jones et al., 2009; Steinbrecht et al., 2009; Newchurch et al., 2003). Since our results are based on data from 2002-2012, after the beginning of the expected turnaround, when they are compared to previous studies, the time span of those data should be kept in mind.

Jones et al. (2009) estimated results based on a variety of satellite ozone data, from $60^{\circ} \mathrm{S}$ to $60^{\circ} \mathrm{N}$ latitudes, from 20 to $45 \mathrm{~km}$, and from 1979 to 2008 . The data are averaged in nine latitude $\left(60^{\circ} \mathrm{S}-30^{\circ} \mathrm{S}, 30^{\circ} \mathrm{S}-30^{\circ} \mathrm{N}, 30^{\circ} \mathrm{N}-60^{\circ} \mathrm{N}\right)$ and altitude $(20-25,25-35,35-45 \mathrm{~km})$ bins. They found that up to 1997 , the trends were generally negative. They state that "after 1997 we find in most cases that the decline of ozone has slowed down although the fitted recoveries are not statistically significant in any of the bins." The authors Steinbrecht et al. (2009) also compared trends for the pre- and post-1997 data, and state:

At all the stations considered here, i.e. from $45^{\circ} \mathrm{S}$ to $45^{\circ} \mathrm{N}$, upper stratospheric ozone has been declining by $10-15 \%$ from 1979 to the end of the 1990s. This decline is consistent with early predictions of ozone destruction by increasing anthropogenic CFCs (Crutzen, 1974). Since the late 1990s, the ozone decline has not continued. At most stations, ozone even appears to be increasing in recent years, in good agreement with model simulations by the Chemistry Climate Model Validation Activity (Eyring et al., 2006).

As seen in the upper row of Fig. 2, for the stratosphere $(20-50 \mathrm{~km})$ at latitudes poleward of $\sim 20^{\circ}$, except for northern latitudes between $\sim 25$ and $30 \mathrm{~km}$, the ozone trends are positive (red, brown colors), with the ozone increasing up to $\sim 5 \%$ decade $^{-1}$. We note that where the trend is negative (green colors, $25-30 \mathrm{~km}$ northern latitudes), the trend is not statistically significant, whereas in both hemispheres when the trends are positive, they are statistically significant $(\sim 5 \sigma$ to more than $10 \sigma$ ). Figure A1 of Appendix A plots the statistical significance of the trends corresponding to Fig. 2.

These support the apparent turnaround in ozone presented by the WMO (2010) at mid-latitudes from 20 to $50 \mathrm{~km}$, based on data taken after the turnaround period, from 1996-2008 (their Fig. 2-7b). Our results also agree qualitatively with their model simulations at northern midlatitudes for the time period 2000-2009. The model simulations show a local maximum near $20 \mathrm{~km}\left(\sim 2 \% \mathrm{decade}^{-1}\right)$, a minimum near $30 \mathrm{~km}\left(<0.5 \%\right.$ decade $\left.^{-1}\right)$ and another maximum near $40 \mathrm{~km}\left(\sim 2 \% \mathrm{decade}^{-1}\right)$. Our results at $45^{\circ} \mathrm{N}$ latitude show positive trends near $20 \mathrm{~km}$, minimum near $25 \mathrm{~km}\left(\sim-0.1 \%\right.$ decade $\left.^{-1}\right)$ and a maximum near $40 \mathrm{~km}$ of $\sim 2 \% \mathrm{decade}^{-1}$. For the southern mid-latitudes, the WMO (2010) reports that there are not enough measurements in general and that the model simulations are smaller than trends derived from measurements at the northern latitudes. We show more broad positive trends in the southern midlatitudes both in area and in amplitude.

Generally then, our results corroborate those presented by the WMO (2010) in the Northern Hemisphere mid-latitudes, and consolidate results in the Southern Hemisphere. 
What potentially completes our general agreement with WMO (2010) is that, in the tropics, in contrast to those at mid-latitudes, our ozone trends are negative (green, blue colors) from $\sim 25$ to $50 \mathrm{~km}$, with a minimum (largest magnitude) of about $-7 \%$ decade $^{-1}$ near $35 \mathrm{~km}$, with values decreasing to $\sim-0.1 \%$ decade $^{-1}$ at $25 \mathrm{~km}$ and at $45 \mathrm{~km}$. The WMO (2010) model simulations (their Fig. 2-27) between $15^{\circ} \mathrm{S}$ and $15^{\circ} \mathrm{N}$ also show negative trends, with minimum magnitudes near $25 \mathrm{~km}$ and $50 \mathrm{~km}$ of less than $-0.1 \%$ decade $^{-1}$ and a maximum value of $\sim-4 \%$ decade $^{-1}$ near $40 \mathrm{~km}$. Their empirical results, based on SAGE (Stratospheric Aerosol and Gas Experiment) and SAGE II data, also indicate similar negative trends in the tropics, but there is inference that they are more tentative and not as robust. It appears that although the tropical profile trends of the WMO (2010) are based on pre-turnaround conditions, it is not clear if WMO (2010) suggests that they also apply to the post-turnaround period. In either case, our results show that, for tropical latitudes, the post-turnaround period is similar to their pre-turnaround period, which either agrees and supports the WMO results, or augments and extends their results, at least qualitatively.

The WMO (and references therein) attribute the negative trend in the stratosphere at least in part to dynamics.

These agreements with WMO (2010) provide added confidence for both their and our results, and our more detailed results can help further analysis across the range of latitudes and altitudes.

Our ozone trends in Fig. 2 do not agree well with corresponding plots of McLinden et al. (2009), Randel and Wu (2007) and WMO (2010, their Fig. 2-4). The disagreement may be because their data also cover many years before the expected turning point starting the late 1990s.

We note that in the tropics where we show negative trends, the above references show trends that are essentially zero, in contrast to other areas where the trends are uniformly negative.

\subsubsection{Stratospheric temperature}

As seen in the lower row of Fig. 2, like the case for ozone, there are both positive (brown, red colors) and negative (green, blue colors) temperature trends in the stratosphere (20 to $50 \mathrm{~km})$.

The positive temperature trends are near the equator, centered near $35 \mathrm{~km}$ (red, brown colors), and at approximately $24^{\circ} \mathrm{N}$ and at $24^{\circ} \mathrm{S}$, around $25 \mathrm{~km}$, with values approaching $1 \mathrm{~K} \mathrm{decade}^{-1}$. Between 30 and $50 \mathrm{~km}$, and poleward of $\sim 15^{\circ}$ latitude, the temperature trends are negative (green, blue colors) and can approach $\sim 2 \mathrm{~K} \mathrm{decade}^{-1}$, except for the small positive "excursions" near $45 \mathrm{~km}$ and $20^{\circ} \mathrm{S}$ latitude. Because our positive temperature trends do not appear to be supported by other studies, it is reasonable to question their validity.

As discussed in Sect. 3, in Fig. 2, it is straightforward to discern positive or negative ozone-temperature correlations simply by comparing the respective colors alone. In the middle and upper stratosphere $(\sim 30-50 \mathrm{~km})$, when the temperature trends are negative (green, blue), the ozone trends are positive (brown, red), and vice versa, except at the equator above $40 \mathrm{~km}$. Thus, the temperature and ozone trends are mostly negatively correlated to each other between 30 and $50 \mathrm{~km}$. It was also noted in Sect. 3 that this negative correlation might be expected, and is consistent with the view that in this altitude range, the ozone concentration is determined more by photochemistry. In the lower stratosphere (below $\sim 25 \mathrm{~km}$ ), it is seen that the respective trends are more positively correlated, as both the temperature and ozone trends are mostly positive (brown, red), except for temperature south of $\sim 35^{\circ} \mathrm{S}$ latitude. This generally positive correlation is consistent with the view that below $\sim 25 \mathrm{~km}$, the ozone concentration is determined more by dynamics than by photochemistry. We will see later that above $\sim 85 \mathrm{~km}$, the ozone-temperature correlation is also positive, again consistent with the view that dynamics is more in control. The probability that these expected correlations are accidental or fortuitous is of course very small, and this provides added support for the validity of the results.

The expected correlations just described between ozone and temperature are also evident in Fig. 3, which shows our derived trends separately for the first half of the solar cycle (2002-2007, approx. solar max to solar min) and the second half.

As noted earlier, in our analysis of ozone and temperature QBO and SAO based on SABER data (Huang et al., 2008), we have found that the corresponding correlations agree, being mostly positive in the lower stratosphere and lower thermosphere, with negative correlations in the upper stratosphere and mesosphere.

In order to acknowledge different views, we note that it has been argued that if ozone is depleted, less radiation is absorbed, thereby reducing the temperature. In addition, dynamics can also contribute. Both of the considerations can lead to positive ozone-temperature correlations. As noted earlier, the WMO (2010) states, "Although the simulated [model ozone] upward trends and trends from measurements are broadly consistent, the observed increase cannot presently be attributed to ODS decrease because of observational uncertainty, natural ozone variability, and stratospheric cooling. Note that both stratospheric cooling and ODS decrease lead to a projected upper stratospheric ozone increase."

For stratospheric temperature, unlike the situation for stratospheric ozone, there are less previous studies with which to compare, and where there are past analysis, the comparison of trends are not as good as that for ozone.

Thompson et al. (2012) reviewed data from the Stratospheric Sounding Unit (SSU) on the NOAA operational satellites. These date back to 1979 , and consequently have been commonly used for trend estimation. For various reasons, the data have undergone reprocessing and the new 
versions provide results that are at variance with those from earlier processing. Thompson et al. (2012) presented model results in addition to empirical trends, and there are significant differences there as well. Compared to our results, the situation is not better, as mentioned earlier; we see positive trends around the equator and others do not, and we do not agree in other respects as well. In addition, some recent studies (Steinbrecht et al., 2009; Keckhut et al., 2011) have found that the previously found negative temperature trends $\left(\sim 1 \mathrm{~K} \mathrm{decade}^{-1}\right)$ in the upper stratosphere may have been erroneous, and the temperatures have instead remained more or less constant since the mid-1980s. Keckhut et al. (2011) analyzed lidar and SSU temperature measurements and also noted that the cooling ended in the early 1990s, followed by a "null trend (slight warming)" after 1994. However they did not separate the data into different periods and analyzed the data set from 1979-2005 together. Their trends at the lidar stations showed, with the exception of positive trends near $80 \mathrm{~km}$, negative values from 30 to near $90 \mathrm{~km}$ of about $4 \mathrm{~K}$ decade $^{-1}$ or less.

With the above caveats in mind, we compare with some previous studies. At low latitudes, our temperature trends are positive at $20 \mathrm{~km}$, reach a minimum near $25 \mathrm{~km}\left(\sim-1.5 \mathrm{~K} \mathrm{decade}^{-1}\right)$, maximizes near $35 \mathrm{~km}\left(\sim 1.5 \mathrm{Kdecade}^{-1}\right)$, and then generally decrease with altitude, reaching a minimum near $75 \mathrm{~km}$ $\left(\sim-3 \mathrm{~K} \mathrm{decade}^{-1}\right)$. At mid-latitudes near $36^{\circ} \mathrm{S}$, a minimum of $\sim-2.5 \mathrm{~K} \mathrm{decade}^{-1}$ is reached at $\sim 35 \mathrm{~km}$, above which the magnitudes decrease to $\sim-1 \mathrm{~K} \mathrm{decade}^{-1}$ near $50 \mathrm{~km}$. In the Northern Hemisphere near $36^{\circ} \mathrm{N}$ latitude, the variation with increasing altitude is similar, but the minimum occurs near $40 \mathrm{~km}$.

At higher altitudes, from $\sim 30$ to $50 \mathrm{~km}$ we compare with Fig. 22b of Randel et al. (2009), who present results based on satellite data (SSU) and three lidar stations at Table Mountain Facility $\left(34^{\circ} \mathrm{N}\right)$, Haute-Provence Observatory $\left(44^{\circ} \mathrm{N}\right)$ and Hohenpeißenberg $\left(48^{\circ} \mathrm{N}\right)$. As can be seen from Fig. 2 near $30 \mathrm{~km}$ and above $\sim 35^{\circ} \mathrm{N}$ latitude, we show remnants of positive trends with increasing altitude, above which the trend becomes negative and approaches $\sim 1 \mathrm{~K} \mathrm{decade}^{-1}$. This agrees best with the results from Haute-Provence $\mathrm{Ob}$ servatory at $44^{\circ} \mathrm{N}$ which show a positive trend near $30 \mathrm{~km}$, which becomes negative near $37 \mathrm{~km}$ and maximizes near $45 \mathrm{~km}$ at just under $1 \mathrm{~K}$. The agreements with the two other stations are not good.

For low latitudes, Keckhut et al. (1999) analyzed rocketsonde temperature data at latitudes $8^{\circ} \mathrm{S}, 9^{\circ} \mathrm{N}, 17^{\circ} \mathrm{N}$, $22^{\circ} \mathrm{N}, 28^{\circ} \mathrm{N}, 34^{\circ} \mathrm{N}$. The trends are all negative, averaging $\sim 2 \mathrm{~K} \mathrm{decade}^{-1}$ from 20 to $50 \mathrm{~km}$, and between $\sim 1$ to $3 \mathrm{Kdecade}^{-1}$ (with more variability) from 50 to $\sim 75 \mathrm{~km}$. Although they do not show the warming trend that we do between $\sim 30$ and $40 \mathrm{~km}$, above $40 \mathrm{~km}$, the magnitudes of the Keckhut et al. (1999) and our trends above 40 km are consistent.
Figure 5 of Ramaswamy et al. (2001), based on satellite measurements from the SSU and Microwave Sounding Unit (MSU), can be directly compared with our Fig. 2, bottom row. Their contours show negative temperature from $\sim-0.5 \mathrm{~K}$ at the lower altitudes to $\sim-2.0 \mathrm{~K}$ above $40 \mathrm{~km}$. There are no positive trends, and the larger magnitudes appear weighted towards the northern latitudes.

Other lidar measurements also generally show results of negative tenths of $\mathrm{K}$ per decade up to $\sim-3 \mathrm{Kdecade}^{-1}$. Although the general magnitudes are similar to ours, we do not discern similar relative variations.

\subsection{Mesospheric ( $(50$ to $\sim 85 \mathrm{~km})$ ozone and temperature}

Compared to lower altitudes, there are less long-term global measurements of ozone and temperature because operational satellites have routinely concentrated on the stratosphere, and relatively more measurements are ground-based, with less spatial coverage. For temperature, as first pointed out by Roble and Dickinson (1989) and others (e.g., Akmaev et al., 2006), in contrast to global warming near ground level, the mesosphere and thermosphere temperature trends are expected to be negative due to the increase in greenhouse gases such as $\mathrm{CO}_{2}$ and $\mathrm{CH}_{4}$, and in large part due to their role in radiative cooling. In the following, we compare temperature trends with selected previous measurements. Beig (2006, 2011a, b), and Beig et al. (2003) have reviewed temperature trends in detail, and we will refer mostly to them and the references therein.

\subsubsection{Mesospheric ozone (50 to $\sim 85 \mathrm{~km})$}

For ozone in the mesosphere (50 to $\sim 85 \mathrm{~km}$ ) at low latitudes, as seen in Fig. 2 (top row), the trend is more positive than negative, but they are mostly not statistically significant. The contours between brown and green areas denote the zero trend line, with brown and red areas being positive. Unlike that for other altitudes, the correlations between ozone and temperature trends in the mesosphere are not clear, and inferences cannot be made from our results even though the temperature trends are negative.

Remsberg (2009) presents mesospheric ozone trends based on data from the Halogen Occultation Experiment (HALOE) on the Upper Atmosphere Research Satellite (UARS). Between 50 and $60 \mathrm{~km}$ at low latitudes, the trend values are essentially zero, consistent with our results. They show negative trends of $\sim-2 \%$ to $4 \%$ decade $^{-1}$ at midlatitudes near $50 \mathrm{~km}$, which we do not show.

\subsubsection{Mesospheric temperature (50 to $\sim 85 \mathrm{~km})$}

As seen in Fig. 2, in the mesosphere, with the exception of two areas near $44^{\circ}$ latitudes (north and south) near $70 \mathrm{~km}$, the trends are negative and can approach $-3 \mathrm{Kdecade}^{-1}$ $\left(\sim 1 \%\right.$ decade $\left.^{-1}\right)$ near the equator, and are also mostly significant between 50 and $80 \mathrm{~km}$ (see Fig. A1). 


\subsection{Upper mesosphere-lower thermosphere (MLT, 85 to $100 \mathrm{~km}$ ) ozone and temperature}

We are not aware of previous published results of ozone trends in the thermosphere. For temperature, there does not appear to be previous results of global trends, and we compare with ground-based measurements. So the spatial coverage is even more limited than in the mesosphere.

In the lower thermosphere ( $~ 85$ to $100 \mathrm{~km})$, our ozone trends become negative, and can approach $10 \%$ decade $^{-1}$ as altitude increases. The values are statistically significant, and can approach $10 \sigma$ or more. Above $\sim 85 \mathrm{~km}$, the ozone and temperature trends are positively correlated, like that in the lower stratosphere, as photochemistry is no longer in control at these altitudes.

As seen in Fig. 2, for temperatures in the lower thermosphere, with the exception of one area at $100 \mathrm{~km}$ and $\sim 35^{\circ} \mathrm{N}$ latitude, the trends are negative, and can approach $3 \mathrm{Kdecade}^{-1}\left(\sim 1 \%\right.$ decade $\left.^{-1}\right)$ at mid-latitudes. Like that for ozone, the trends are statistically significant above $\sim 85$ $90 \mathrm{~km}$ (except for the positive trend near $100 \mathrm{~km}, 35^{\circ} \mathrm{N}$ latitude). Offermann et al. (2010) measured temperatures centered around $87 \mathrm{~km}$ from $\mathrm{OH}$ airglow over Wuppertal (Germany, $51^{\circ} \mathrm{N}, 7^{\circ} \mathrm{E}, 8 \mathrm{~km}$ layer) from 1998 to 2008 and estimated the trend to be $-2.3 \mathrm{Kdecade}^{-1}$. This agrees well with our results in Fig. 2 at $48^{\circ} \mathrm{N}$ latitude. This agreement is perhaps significant in that, as can be seen in Fig. 2, the area near $87 \mathrm{~km}$ and $48^{\circ} \mathrm{N}$ contains values that are especially high. She et al. (2009), using lidar, measured temperatures between 85 and $105 \mathrm{~km}$ over Fort Collins (CO., $41^{\circ} \mathrm{N}$, $105^{\circ} \mathrm{W}$ ) from 1990 to 2007. Accounting for Mount Pinatubo, their trends are negative and the magnitudes peak near $91 \mathrm{~km}$ with a value of $\sim-1.3 \mathrm{~K} \mathrm{decade}^{-1}$ and turns positive near $102 \mathrm{~km}$. This agrees well with our results, including the positive trend that we see at $100 \mathrm{~km}$. As altitude decreases below $91 \mathrm{~km}$, the magnitude of their negative trends decreases and reaches $\sim 0$ at $85 \mathrm{~km}$, their lowest altitude. Our results show a similar decrease in magnitudes, but they do not reach zero until $\sim 70 \mathrm{~km}$.

As with the case for ozone noted in Sect. 3.3.1, the potential of aliasing is also possible for temperature. However, the reasonable agreement between our results and those of Offermann et al. (2010) and She et al. (2009) should mitigate concerns on this issue.

\subsection{Solar cycle influences}

Although solar cycle influences per se are outside the scope of this study, we present a first look (smell test) of the trends and further present ozone-temperature correlations over periods of years. However, a longer data set may be needed to adequately identify and separate the influences due to solar activity from that due to other considerations such as photochemistry and dynamics. Consequently, we will not discuss more details or refer to previous studies.
As noted earlier, our temperature trends in Fig. 3 (bottom left plot) agree well with those of $\mathrm{Xu}$ et al. (2007), considering that their results are based on an earlier version of SABER data and that the time spans differ by some months. In comparing with $\mathrm{Xu}$ et al. (2007), it should be noted that our trend values are normalized to differences per decade. They state that their results satisfy the $95 \%$ confidence level, and consequently our trends also would satisfy this significance criteria.

Figure 3 shows corresponding trends based on SABER data from 2002-2007 (approx. solar max to solar min) and from 2007-2012 (approx. solar min to solar max) for ozone (top row) and temperature (bottom row). For ozone, it can be seen that, except at the lowest altitudes, trends based on data from 2002 to 2007 (top row, left plot) are essentially near zero (brown-green areas denote zero contour borders, with brown and red areas denoting positive trends) or negative, while the trends based on data from 2007 to 2012 (right plot) are near zero or positive.

\section{Summary}

We have presented estimates of ozone and temperature trends based on SABER data from 2002 through 2012, from $48^{\circ} \mathrm{S}$ to $48^{\circ} \mathrm{N}$ latitude, and from 20 to $100 \mathrm{~km}$, in the stratosphere, mesosphere and lower thermosphere. SABER measurements provide an entirely new data set for ozone and temperature trends as we are not aware of any comparable results covering this time period and spatial extent. For the first time, trends of ozone and temperature measured at the same times and locations are obtained, and their correlations should provide useful information about the relative importance of photochemistry versus dynamics over the longer term.

\subsection{Stratosphere}

For stratospheric ozone, our trends support the results of the WMO (2010) and references therein, which show that at northern mid-latitudes, in contrast to periods before $\sim 1996$, ozone trends have become positive (increasing ozone amounts). Our results verify the apparent turnaround in ozone trends. However, the WMO (2010) notes that their observed increase cannot presently be attributed to ozonedepleting substances (ODS) in part because of observational uncertainty. Our results, based on completely independent measurements, should go some way in addressing the empirical issues cited by the WMO. For the southern mid-latitudes, the WMO (2010) reports that more measurements are needed and that the model simulations are smaller than trends derived from measurements at the northern latitudes. We show broader positive trends in the southern mid-latitudes both in area and in amplitude. Where the WMO (2010) have ozone trends with which we can compare directly, comparisons are 

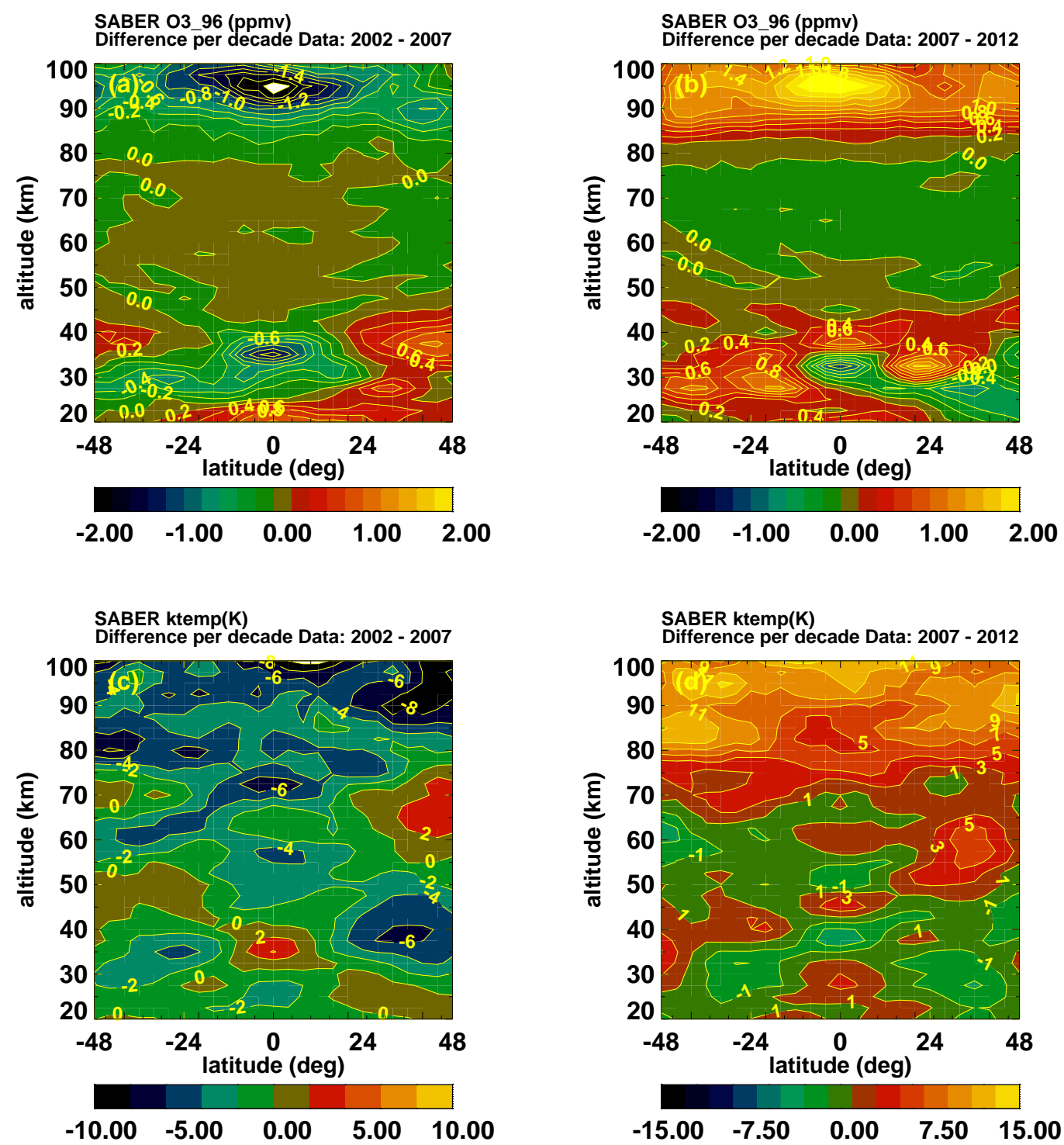

Figure 3. Ozone and temperature trends on altitude $(20$ to $100 \mathrm{~km})$ vs. latitude $\left(48^{\circ} \mathrm{S}\right.$ to $\left.48^{\circ} \mathrm{N}\right)$. Top row: ozone trends from 2002 to 2007 (declining solar activity; left); ozone trends from 2007 to 2012 (increasing solar activity; right). Bottom row: as in top row, but for temperature. Brown-green areas denote zero contour borders, with brown and red areas denoting positive trends.

quite consistent, at least qualitatively. Where previous results are limited, our results augment and extend them.

What completes the agreement in the stratosphere is that in the tropics, in contrast to those at mid-latitudes, our ozone trends are negative from $\sim 25$ to $50 \mathrm{~km}$. This agrees with the WMO model simulations, and with their empirical results, based on SAGE and SAGE II data, although the latter may be more tentative. A caveat is that it is not clear if the WMO simulations in the tropics are applicable only to the pre-turnaround period, or also apply to the post-turnaround. In any case, our results either agree qualitatively with those given by the WMO, or extend them to the post-turnaround period.
Our stratospheric temperature trends, like those for ozone, can be both positive and negative. However, they are generally negatively correlated with the ozone trends from $\sim 30$ to $50 \mathrm{~km}$, and mostly positively correlated below $\sim 25 \mathrm{~km}$ (and above $85 \mathrm{~km}$ ). These relative variations between ozone and temperature have been noticed in previous studies of ozone and temperature perturbations, although not for trends.

\subsection{Mesosphere}

The correlations are not so clear in the mesosphere (50 to $85 \mathrm{~km}$ ) because the ozone trends are only marginally (barely) positive at low latitudes and are not statistically significant. Consequently, the accepted trend value for ozone would be zero. 


\subsection{Upper mesosphere-lower thermosphere}

In the lower thermosphere ( $~ 85$ to $100 \mathrm{~km})$, both ozone and temperature trends are generally negative, and so they are positively correlated with each other. The ozone trends are new, with no previous results with which to compare. The temperature trends compare favorably with some previous results (although they are scarce), such as those of Offermann et al. (2010) and She et al. (2009).

The correlations in our ozone-temperature trends strongly support the validity of each other, as the probability that the correlations are fortuitous is extremely small.

Concerning the quality of our results, as discussed earlier in the text, the salient features in Fig. 2 are generally well above the statistical significance level of $2 \sigma$. To further support the validity of our results, we have seen the following:
1. Our ozone trends in the stratosphere, where direct comparisons can be made, agree well qualitatively with previous studies (e.g., WMO, 2010).

2. As just noted, our ozone-temperature trend correlations are consistent with many previous studies of ozonetemperature perturbations (other than trends), including relatively long time spans covering many years. The correlations strongly support our results, for both ozone and temperature. The chances that the strong negative and positive correlations are coincidental are very low.

3. Our temperature results compare well with those of $\mathrm{Xu}$ et al. (2007), also based on SABER data. Xu et al. (2007) state that their trends meet the $95 \%$ confidence level, which then implies the same for our results. 


\section{Appendix A: Statistical significance of trends}

As noted above, a commonly used criteria to indicate if an estimated trend is statistically significant, is that its magnitude be greater than $2 \sigma(\sim 95 \%$ confidence level $)$, where $\sigma$ is the uncertainty of the trend estimate. The right plots (top and bottom row) of Fig. A1 show the ratio of the trends to their respective uncertainties for ozone and temperature, respectively, on altitude-latitude coordinates. The left plots correspond to the right plots, but show the corresponding trends themselves, as in Fig. 2. In the right hand plots, the brown colors correspond to a value of 2 for the ratios of the magnitude of the trends to their respective uncertainties, $\sigma$, and mark the level of statistical significance. The red and yellow colors in the right hand plots correspond to situations that are statistically significant (greater than 2), while the green colors correspond ratios of less than 2 . The brighter yellow colors are a result of the ratios beings larger than the upper plot limit. The lower plot limit is set to negative so that the brown color demarks the significance of the results.

\section{Appendix B: Additional data quality considerations}

The SABER instrument on TIMED has been making measurements for more than 12 years, and it is useful to review potential issues that can affect the interpretation of trends derived from the data. These include the satellite orbital motions and possible changes in the instrument performance.

An example related to orbital motion is data from the operational polar orbiter satellites, which have been used by a large number of previous studies for trends. The advantage is that the various orbiters together span many decades. However, problems exist in that the data from orbiters and their successors need to be matched, and that over time, the orbits can, and some have, drifted from their nominal characteristics.

The operational polar orbiters generally measure data at a constant local time, one for the ascending mode (northward bound) and one for the descending mode. Global coverage over different longitudes is made once per day by the polar orbits as the globe rotates beneath relative to the orbital plane. The local times at which the measurements are made are independent of longitude and, ideally, this would hold throughout the mission. Consequently, trends derived from these data correspond to one local time.

However, in some cases the orbital plane has drifted and, as a result, the measurements are then made at different local times. Both ozone and temperature variations can be a strong function of local time (e.g., atmospheric tides). Because orbital drifts may result in local time changes that are limited, not over $24 \mathrm{~h}$, it is problematical to separate variations as a function of local time from others, such as season.
The situation for SABER on the TIMED satellite is different. The orbit of TIMED is inclined at $74^{\circ}$, and as such, the orbital plane precesses at a regular rate so that from day to day the local times at which the data are measured decrease by $12 \mathrm{~min}$, and it take 60 days to sample over the $24 \mathrm{~h}$ of local time. The important difference here is that the data are sampled over the $24 \mathrm{~h}$ of local time. This provides the opportunity to separate the variations with local time from those as a function of other variables, such as season. Using SABER data, we had previously estimated the variations with local times of ozone and temperature. In this way, we can estimate not only variations with local time, but we can also average over local time variations to obtain true mean variations, which are then used for trend estimates. We have briefly discussed this Sect. 2.2.1 of the manuscript. More details are given in Huang et al. (2008), where we have used the mean values to generate estimates of the annual, semiannual and quasi-biennial oscillations. In Huang et al. (2010a, b), we discuss the local time variations.

Up to now, the orbit of TIMED has been stable. But even if orbital drifts do occur in the future, we will be able account for their effects.

As for instrument performance and degradation, the SABER principal investigator is also an author of this manuscript. In-flight calibrations and analysis of the instruments components are made routinely. Usually, the data themselves cannot provide much information on instrument degradation. However, for our case, we have an advantage in being able to compare with previous studies, which also analyzed other data over a decade or more. Importantly, the comparisons are very favorable. As discussed in the manuscript, our ozone trends compare very well with those of the WMO (2010), and our temperature trends compare well with ground-based measurements of She et al. (2009) and of Offerman et al. (2010). In addition, our ozone and temperature trends in Fig. 2 show various positive and negative trends in various regions. For example, as discussed in the manuscript, it is expected that in the middle and upper stratosphere, the ozone and temperature trends would be negatively correlated. As seen in Fig. 2 of the manuscript, near $35 \mathrm{~km}$ altitude and the Equator, the ozone trends are negative (top left plot), while the temperature trends are positive (bottom left). With increasing latitude, between 10 and $20^{\circ} \mathrm{N}$, the ozone trends change from negative to positive, while the temperature trends change from positive to negative. As discussed in the manuscript, this anti-correlation is expected. The fact that they cross the zero values at the same locations with one increasing in value and the other decreasing in value also indicates that instrument degradation is not an issue. Instrument degradation would likely undo this co-variation. 

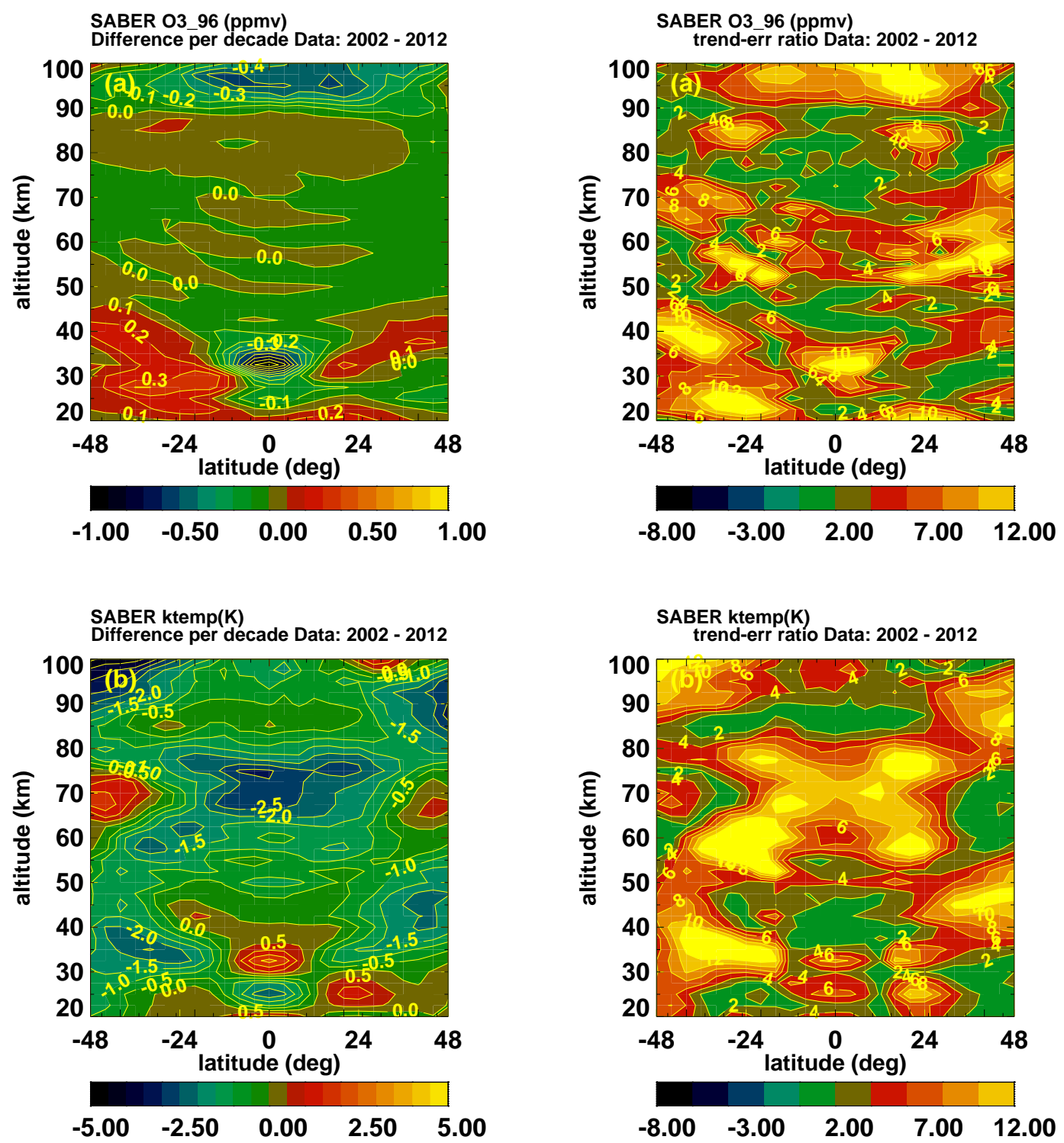

Figure A1. Top row: ozone trends (top left) and ratios to their respective uncertainties (top right). Bottom row: corresponds to top row, but for temperatures. 
Acknowledgements. We thank the editor, C. Jacobi, and two anonymous referees, whose insightful comments helped to improve this paper.

Topical Editor C. Jacobi thanks three anonymous referees for their help in evaluating this paper.

\section{References}

Akmaev, R. A., Formichev, V. I., and Zhu, X.: Impact of middleatmospheric composition changes on greenhouse cooling in the upper atmosphere, J. Atmos. Sol.-Terr. Phys., 68, 1879-1889, 2006.

Barnett, J. J., Houghton, J. T., and Pyle, A. J.: The temperature dependence of the ozone Concentration near the stratopause, Q. J. Roy Meteorol. Soc., 101, 245-257, 1975.

Beig, G.: Trends in the mesopause region temperature and our present understanding - an update, Phys. Chem. Earth, 31, 3-9, 2006.

Beig, G.: Long-term trends in the temperature of the mesosphere/lower thermosphere region: 1. Anthropogenic influences J. Geophys. Res., 116, A00H11, doi:10.1029/2011JA016646, 2011a.

Beig, G.: Long-term trends in the temperature of the mesosphere/lower thermosphere region: 2. Solar response, J. Geophys. Res., 116, A00H12, doi:10.1029/2011JA016766, $2011 \mathrm{~b}$.

Beig, G., Keckhut, P., Lowe, R. P., Roble, R. G., Mlynczak, M. G., Scheer, J., Fomichev, V. I., Offermann, D., French, W. J. R., Shepherd, M. G., Semenov, A. I., Remsberg, E. E., She, C. Y., Lübken, F. J., Bremer, J., Clemesha, B. R., Stegman, J., Signernes, F., and Fadnavis, S.: Review of Mesospheric Temperature Trends, Rev. Geophys., 41, 1015, doi:10.1029/2002RG000121, 2003.

Bevington, P. R. and Robinson, D. K.: Data reduction and error analysis for the physical sciences, McGraw-Hill, New York, USA, 1992.

Brasseur, G. P. and Solomon, S.: Aeronomy of the Middle Atmosphere, Springer, Dordrecht, The Netherlands, 2005.

Crutzen, P. J.: Estimates of possible future ozone reductions from continued use of fluoro-chloro-methanes $\mathrm{CF} 2 \mathrm{Cl} 2, \mathrm{CFCl} 3$, Geophys. Res. Lett., 1, 205-208, 1974.

Douglass, A. R., Rood, R. B., and Stolarski, R. S.: Interpretation of ozone temperature correlations 2. Analysis of SBUVozone data, J. Geophys. Res., 90, 10693-10708, 1985.

Eyring, V., Butchart, N., Waugh, D. W., Akiyoshi, H., Austin, J., Bekki, S., Bodeker, G. E., Boville, B. A., Brühl, C., Chipperfield, M. P., Cordero, E., Dameris, M., Deushi, M., Fioletov, V. E., Frith, S. M., Garcia, R. R., Gettelman, A., Giorgetta, M. A., Grewe, V., Jourdain, L., Kinnison, D. E., Mancini, E., Manzini, E., Marchand, M., Marsh, D. R., Nagashima, T., Newman, P. A., Nielsen, J. E., Pawson, S., Pitari, G., Plummer, D. A., Rozanov, E., Schraner, M., Shepherd, T. G., Shibata, K., Stolarski, R. S., Struthers, H., Tian, W., and Yoshiki, M.: Assessment of temperature, trace species, and ozone in chemistry climate model simulations of the recent past, J. Geophys. Res., 111, D22308, doi:10.1029/2006JD007327, 2006.

Finger, F. G., Nagatani, R. M., Gelman, M. E., Long, C. S., and Miller, A. J.: Consistency between variations of ozone and temperature in the stratosphere, Geophys. Res. Lett., 22, 3477-3480, 1995.
Garcia, R. R. and Solomon, S.: The Effect of Breaking Gravity Waves on the Dynamics and Chemical Composition of the Mesosphere and Lower Thermosphere, J. Geophys. Res., 90, 38503868, 1985.

Huang, F. T., Mayr, H. G., Reber, C. A., Russell III, J. M, Mlynczak, M. G., and Mengel, J. G.: Ozone quasi-biennial oscillations (QBO), semiannual oscillations (SAO), and correlations with temperature in the mesosphere, lower thermosphere, and stratosphere, based on measurements from SABER on TIMED and MLS on UARS, J. Geophys. Res., 113, A01316, doi:10.1029/2007JA012634, 2008.

Huang, F. T., McPeters, R. D., Bhartia, P. K., Mayr, H. G., Frith, S. M., Russell III, J. M., and Mlynczak, M. G.: Temperature diurnal variations (migrating tides) in the stratosphere and lower mesosphere based on measurements from SABER on TIMED, J. Geophys. Res., 115, D16121, doi:10.1029/2009JD013698, 2010a.

Huang, F. T., Mayr, H. G., Russell III, J. M., and Mlynczak, M. G.: Ozone diurnal variations in the stratosphere and lower mesosphere, based on measurements from SABER on TIMED, J. Geophys. Res., 115, D24308, doi:10.1029/2010JD014484, $2010 b$.

Jones, A., Urban, J., Murtagh, D. P., Eriksson, P., Brohede, S., Haley, C., Degenstein, D., Bourassa, A., von Savigny, C., Sonkaew, T., Rozanov, A., Bovensmann, H., and Burrows, J.: Evolution of stratospheric ozone and water vapour time series studied with satellite measurements, Atmos. Chem. Phys., 9, 6055-6075, doi:10.5194/acp-9-6055-2009, 2009.

Keckhut, P., Schmidlin, F. J., Hauchecorne, A., and Chanin, M. L.: Stratospheric and mesospheric cooling trend estimates from US rocketsondes at low latitude stations, $\left(8^{\circ} \mathrm{S}-34^{\circ} \mathrm{N}\right)$, taking into account instrumental changes and natural variability, J. Atmos. Sol.-Terr. Phys., 61, 447-459, 1999.

Keckhut, P., Randel, W. J., Claud, C., Leblanc, T., Steinbrecht, W., Funatsu, B. M., Bencherif, H., McDermid, Hauchecorne, A., Long, C., Lin, R., and Baumgarten, G.: An evaluation of uncertainties in monitoring middle atmosphere temperatures with the ground-based lidar network in support of space observations, J. Atmos. Sol.-Terr. Phys., 73, 627-642, 2011.

Kohlhepp, R., Ruhnke, R., Chipperfield, M. P., De Mazière, M., Notholt, J., Barthlott, S., Batchelor, R. L., Blatherwick, R. D., Blumenstock, Th., Coffey, M. T., Demoulin, P., Fast, H., Feng, W., Goldman, A., Griffith, D. W. T., Hamann, K., Hannigan, J. W., Hase, F., Jones, N. B., Kagawa, A., Kaiser, I., Kasai, Y., Kirner, O., Kouker, W., Lindenmaier, R., Mahieu, E., Mittermeier, R. L., Monge-Sanz, B., Morino, I., Murata, I., Nakajima, H., Palm, M., Paton-Walsh, C., Raffalski, U., Reddmann, Th., Rettinger, M., Rinsland, C. P., Rozanov, E., Schneider, M., Senten, C., Servais, C., Sinnhuber, B.-M., Smale, D., Strong, K., Sussmann, R., Taylor, J. R., Vanhaelewyn, G., Warneke, T., Whaley, C., Wiehle, M., and Wood, S. W.: Observed and simulated time evolution of $\mathrm{HCl}, \mathrm{ClONO}_{2}$, and $\mathrm{HF}$ total column abundances, Atmos. Chem. Phys., 12, 3527-3556, doi:10.5194/acp12-3527-2012, 2012.

McLinden, C. A., Tegtmeier, S., and Fioletov, V.: Technical Note: A SAGE-corrected SBUV zonal-mean ozone data set, Atmos. Chem. Phys., 9, 7963-7972, doi:10.5194/acp-9-7963-2009, 2009.

Mukhtarov, P., Pancheva, D., and Andonov, B.: Global structure and seasonal and interannual variability of the migrat- 
ing diurnal tide seen in the SABER/TIMED temperatures between 20 and $120 \mathrm{~km}$, J. Geophys. Res., 114, A02309, doi:10.1029/2008JA013759, 2009.

Newchurch, M. J., Eun-Su Yang, Cunnold, D. M., Reinsel, G. C., Zawodny, J. M., and Russell III, J. M.: Evidence for slowdown in stratospheric ozone loss: First stage of ozone recovery, J. Geophys. Res., 108, 4507, doi:10.1029/2003JD003471, 2003.

Offermann, D., Hoffmann, P., Knieling, P., Koppmann, R., Oberheide, J., and Steinbrecht, W.: Long-term trends and solar cycle variations of mesospheric temperature and dynamics, J. Geophys. Res., 115, D18127, doi:10.1029/2009JD013363, 2010.

Ramaswamy, V., Chanin, M.-L., Angell, J., Barnett, J., Gaffen, D., Gelman, M., Keckhut, P., Koshelkov, Y., Labitzke, K., Lin, J.-J. R., O’Neill, A., Nash, J., Randel, W., Rood, R., Shine, K., Shiotani, M., and Swinbank, R.: Stratospheric temperature trends: Observations and model simulations, Rev. Geophys., 39, 71-122, 2001.

Randel, W. J. and Wu, F.: A stratospheric ozone profile data set for 1979-2005: Variability, trends, and comparisons with column ozone data, J. Geophys. Res., 112, D06313, doi:10.1029/2006JD007339, 2007.

Randel, W. J., Shine, K. P., Austin, J., Barnett, J., Claud, C., Gillett, N. P., Keckhut, P., Langematz, U., Lin, R., Long, C., Mears, C., Miller, A., Nash, J., Seidel, D. J., Thompson, D. W. J., Wu, F., and Yoden, S.: An update of observed stratospheric temperature trends, J. Geophys. Res., 114, D02107, doi:10.1029/2008JD010421, 2009.

Remsberg, E. E.: Trends and solar cycle effects in temperature versus altitude from the Halogen Occultation Experiment for the mesosphere and upper Stratosphere, J. Geophys. Res., 114, D12303, doi:10.1029/2009JD011897, 2009.

Roble, R. G. and Dickinson, R. E.: How will changes in carbon dioxide and methane modify the mean structure of the mesosphere and thermosphere?, Geophys. Res. Lett., 16, 1441-1444, 1989.

Rood, R. B. and Douglass, A.: Interpretation of Ozone Temperature Correlations 1. Theory, J. Geophys. Res., 90, 5733-5743, 1985.

Russell III, J. M., Mlynczak, M. G., Gordley, L. L., Tansock, J., and Esplin, R.: An overview of the SABER experiment and preliminary calibration results, Proceedings of the SPIE, 44th Annual Meeting, Denver, Colorado, 18-23 July, 3756, 277-288, 1999.

She, C. Y., Krueger, D. A., Akmaev, R., Schmidt, H., Talaat, E., and Yee, S.: Long-term variability in mesopause region temperatures over Fort Collins, Colorado $\left(41^{\circ} \mathrm{N}, 105^{\circ} \mathrm{W}\right)$ based on lidar observations from 1990 through 2007, J. Atmos. Sol. Terr. Phys., 71, 1558-1564, doi:10.1016/j.jastp.2009.05.007, 2009.
Steinbrecht, W., Claude, H., Schönenborn, F., McDermid, I. S., Leblanc, T., Godin-Beekmann, S., Keckhut, P., Hauchecorne, A., Van Gijsel, J. A. E., Swart, D. P. J., Bodeker, G. E., Parrish, A., Boyd, I. S., Kämpfer, N., Hocke, K., Stolarski, R. S., Frith, S. M., Thomason, L. W., Remsberg, E. E., Von Savigny, C., Rozanov, A., and Burrows, J. P.: Ozone and temperature trends in the upper stratosphere at five stations of the Network for the Detection of Atmospheric Composition Change, Int. J. Remote Sens., 30, 3875-3886, doi:10.1080/01431160902821841, 2009.

Thompson, D. W. J., Seidel, D. J., Randel, W. J., Cheng-Zhi Zou, Butler, A. M., Mears, C., Osso, A., Long, C., and Lin, R.: The mystery of recent stratospheric temperature trends, Nature, 491, 692-697, doi:10.1038/nature11579, 2012.

Tiao, G. C., Reinsel, G. C., Xu, D., Pedrick, J. H., Zhu, X., Miller, A. J., DeLuisi, J. J., Mateer, C. L., and Wuebbles, D. J.: Effects of autocorrelation and temporal sampling schemes on estimates of trend and spatial correlation, J. Geophys Res., 95, 20507-20517, 1990.

Weatherhead, E. C., Reinsel, G. C., Tiao, G. C., Xiao-Li Meng, Dongseok C hoi, Wai-Kwong Cheang, Keller, T., DeLuisi, J., Wuebbles, D. J., Kerr, J. B., Miller, A. J., Oltmans, S. J., and Frederick, J. E.: Factors affecting the detection of trends: Statistical considerations and applications to environmental data, J. Geophys. Res., 103, 17149-17161, 1998.

Weatherhead, E. C., Reinsel, G. C., Tiao, G. C., Jackman, C. H., Bishop, L., Hollandsworth Frith, S. M., DeLuisi, J., Keller, T., Oltmans, S. J., Fleming, E. L., Wuebbles, D. J., Kerr, J. B., Miller, A. J., Herman, J., McPeters, R., Nagatani, R. M., and Frederick, J. E.: Detecting the recovery of total column ozone, J. Geophys. Res., 105, 22201-22210, 2000.

World Meteorological Organization (WMO): Scientific assessment of ozone depletion: 2010, Global Ozone Res. Monit. Proj. Rep. 52, Geneva, Switzerland, 2010.

Xu, J., Smith, A. K., Yuan, W., Liu, H.-L., Wu, Q., Mlynczak, M. G., Russell III, J. M.: Global structure and long-term variations of zonal mean temperature observed by TIMED/SABER, J. Geophys. Res., 112, D24106, doi:10.1029/2007JD008546, 2007.

Zhang, X., Forbes, J. M., Hagan, M. E., Russell III, J. M., Palo, S. E., Mertens, C. J., and Mlynczak, M. G.: Monthly tidal temperatures 20-120 km from TIMED/SABER, J. Geophys. Res., 111, A10S08, doi:10.1029/2005JA011504, 2006. 